\title{
Viabilidade econômica da produção de frangos de corte sob diferentes estruturas de governança
}

\author{
[Economic viability of broiler production under \\ different governance structures] \\ E.O.L. Caldas ${ }^{1}$, A.L.R. Lima $^{2}$, L.J.C. Lara ${ }^{1}$ \\ ${ }^{1}$ Escola de Veterinária - Universidade Federal de Minas Gerais - Belo Horizonte, MG \\ ${ }^{2}$ Universidade Federal de Lavras - Lavras, MG
}

\begin{abstract}
RESUMO
Objetivou-se verificar a viabilidade econômica da produção de frangos de corte sob mecanismos de governança híbrida e hierárquica. Estudos de caso foram escolhidos para avaliação da atividade em núcleos de empresas integradoras e de produtores rurais integrados. Realizou-se pesquisa de campo para coleta de dados em 36 unidades de produção em Minas Gerais. Informações provenientes de 216 lotes produzidos entre agosto de 2015 e agosto de 2016 foram utilizadas nas análises econômicas. O cálculo dos custos baseou-se na metodologia proposta pela Embrapa - CNPSA e IEA - SP. As análises econômicas se realizaram conforme proposto pelo DAE - Ufla e pela Conab. Constatou-se que o custo com mão de obra causou maior impacto sobre o desempenho econômico de núcleos com estruturas de governança distintas. No modelo de produção via governança hierárquica, mesmo se considerando receitas secundárias ao processo de produção de aves, verificou-se prejuízo financeiro na atividade. Concluiu-se que a estrutura de governança híbrida representou melhor alternativa econômica que a internalização do processo de criação de frangos pelas empresas integradoras. Assim, sugere-se que empresas integradoras esgotem as possibilidades de produção via contrato de integração antes de investirem recursos em instalações próprias de criação.
\end{abstract}

Palavras-chave: avicultura de corte, custos de produção, estrutura de governança

\begin{abstract}
The objective was to verify the economic feasibility in the production of broilers under hybrid and hierarchical governance mechanisms. Case studies were used to evaluate the activity of the integrating company and the integrated rural producers. The primary data about costs, income, and zootechnical indicators were collected in 36 poultry production units belonging to an integrated company and five rural producers, in state of Minas Gerais. Data from 216 batches of broilers produced between August 2015 and August 2016 were used in the economic analysis. Costs calculation was based on the methodology proposed by EMBRAPA - CNPSA and IEA - SP. The economic analyzes were carried out as proposed by DAE UFLA and CONAB. It was verified that the cost of labor caused the greatest impact on the economic performance of cores with different governance structures. In all breeding sites via hierarchical governance, even considering secondary revenues, there was a financial loss in the activity. It was concluded that the hybrid governance represented a better economic alternative than the internalization of the broiler production by integrating companies. Thus, it is suggested that integrating companies deplete the production possibilities through an integration contract before investing resources in their own breeding facilities.
\end{abstract}

Keywords: poultry, costs production, governance structure

Recebido em 27 de fevereiro de 2019

Aceito em 29 de abril de 2019

E-mail: caldas.eol@gmail.com 


\section{INTRODUÇÃO}

O Brasil é o maior exportador mundial de carne de frango e o segundo maior produtor de frangos de corte. Em comparação com outros sistemas agroindustriais do ramo proteico animal, a avicultura se sobressai por ser aquela que produz o maior volume de carne no mercado brasileiro. Além do sucesso produtivo, a cadeia avícola de corte possui elevada importância socioeconômica para o desenvolvimento nacional, pois a carne de frango é fonte de proteína animal mais consumida no país e o setor congrega mais de três milhões e meio de trabalhadores nas áreas urbana e rural. Projeções do Ministério da Agricultura, Pecuária e Abastecimento - Mapa apontaram que, para o ano de 2025 , a produção de carne de frango será de aproximadamente 17,7 milhões de toneladas, o que representa um acréscimo de $35 \%$ no volume produzido, em comparação com o ano de 2015. Sob essa perspectiva, em uma década, a avicultura brasileira superará o volume de carne produzido em conjunto pela bovinocultura de corte e pela suinocultura nacionais.

Segundo a Associação Brasileira de Proteína Animal - ABPA, o sucesso da avicultura de corte no Brasil deve-se à adoção do "sistema de integração" entre agroindústrias e produtores rurais. Assim, por meio de mecanismos de governança híbrida, empresas abatedoras mantiveram estreito controle sobre a criação das aves, sem que fosse necessário internalizar esse processo dentro de seus limites jurídicos. A despeito dessa tendência modernizadora, observa-se que produtores independentes e empresas integradoras ainda perpetuam estruturas de governança hierárquica, haja vista os investimentos realizados na manutenção e construção de instalações próprias de criação.

Dentro desse contexto, para que a cadeia avícola de corte conserve o intrincado equilíbrio existente entre seus elos e confirme projeções futuras, é necessário que empresas integradoras extrapolem a intuição e o bom senso no momento de expandir suas atividades. Assim, objetivou-se verificar a viabilidade econômica da produção de frangos de corte em núcleos de produtores integrados - governança híbrida - e em núcleos de galpões pertencentes às empresas integradoras - governança hierárquica.

\section{MATERIAL E MÉTODOS}

Abordagem quantitativa da realidade foi utilizada em pesquisa de natureza aplicada para alcançar objetivos por meio de investigação exploratória, descritiva e explicativa. Estudos de casos múltiplos (Yin, 2007) foram adotados para se compararem resultados econômicos obtidos por empresas integradoras e por produtores rurais integrados. Três empresas integradoras e 15 produtores rurais integrados do estado de Minas Gerais, sob garantia do sigilo de nomes e de referências diretas que os pudessem identificar, compuseram a fase de pré-seleção das fontes de dados. Apesar dos critérios adotados, avaliações parciais de verossimilhança e de adequação das informações durante a coleta de dados possibilitaram a inclusão de apenas uma empresa integradora e de cinco produtores rurais integrados a ela vinculados.

Dados financeiros foram obtidos por meio da coleta de informações primárias ou secundárias fornecidas pelas empresas integradoras e pelos produtores rurais integrados. Indicadores $\mathrm{e}$ resultados zootécnicos foram solicitados às empresas integradoras. Os cálculos dos custos de produção de frangos de corte basearam-se em metodologias da Embrapa (Girotto e Souza, 2006; Miele et al., 2010a). A estruturação dos custos realizou-se conforme conceitos propostos pelo Departamento de Administração e Economia da Ufla - DAE Ufla (Reis, 2007) e pelo Instituto de Economia Agrícola do Estado de São Paulo - IEA (Matsunaga et al., 1976). Dessa maneira, os dados foram agrupados em: a) 16 categorias de custo operacional efetivo (COE): mão de obra, calefação, substrato para cama, energia elétrica, manutenção, serviço de apanha, assistência técnica, produtos veterinários, outras despesas, limpeza e desinfecção, eventuais, aluguel, Funrural, seguro, licenciamento ambiental e despesas administrativas; b) duas categorias de custo operacional fixo (COF): mão de obra familiar e depreciação, calculada pelo método linear; c) duas categorias de custo alternativo (CAlt): custo alternativo sobre o COE total e custo alternativo sobre ativo imobilizado, calculados com base no rendimento da caderneta de poupança para o período considerado $(6,25 \%$ ao ano); d) custo operacional total (COT); e) custo total de produção (CT); e f) custos médios de produção 
(CMe), em reais por quilograma de peso vivo produzido por lote.

Para o cálculo dos custos de produção, foram utilizadas informações provenientes de 216 lotes de frangos de corte da linhagem $\mathrm{COBB}^{\circledR}$, produzidos em 36 instalações de criação, entre agosto de 2015 a agosto de 2016. De acordo com a tecnologia de climatização dos aviários, com a localização das instalações de criação, com a alocação de recursos humanos e com a propriedade sobre ativos, dividiram-se as unidades de produção em oito núcleos de produção, sendo três pertencentes à empresa integradora (núcleos IT) e cinco pertencentes aos produtores rurais (núcleos $\mathrm{PR}$ ). As principais características de cada núcleo foram apresentadas na Tab. 1.

Tabela 1. Número de trabalhadores e de unidades de produção nos núcleos de criação

\begin{tabular}{|c|c|c|}
\hline Núcleo & Número de trabalhadores & Unidades de produção \\
\hline Núcleo IT 01 & $\begin{array}{l}26 \text { trabalhadores contratados } \\
\text { permanentes }\end{array}$ & $\begin{array}{l}\text { Oito galpões próprios climatizados por } \\
\text { pressão negativa }\end{array}$ \\
\hline Núcleo IT 02 & $\begin{array}{l}31 \text { trabalhadores contratados } \\
\text { permanentes }\end{array}$ & $\begin{array}{l}11 \text { galpões arrendados climatizados por } \\
\text { pressão positiva }\end{array}$ \\
\hline Núcleo IT 03 & $\begin{array}{l}27 \text { trabalhadores contratados } \\
\text { permanentes }\end{array}$ & $\begin{array}{l}\text { Nove galpões próprios climatizados por } \\
\text { pressão positiva }\end{array}$ \\
\hline Núcleo PR 01 & $\begin{array}{l}\text { O proprietário mais um membro da } \\
\text { família }\end{array}$ & $\begin{array}{l}\text { Dois galpões próprios climatizados por } \\
\text { pressão positiva }\end{array}$ \\
\hline Núcleo PR 02 & $\begin{array}{l}\text { O proprietário e um trabalhador } \\
\text { contratado permanente }\end{array}$ & $\begin{array}{l}\text { Três galpões próprios climatizados por } \\
\text { pressão positiva }\end{array}$ \\
\hline Núcleo PR 03 & $\begin{array}{l}\text { O proprietário e um membro da família } \\
\text { (meio período) }\end{array}$ & $\begin{array}{l}\text { Um galpão próprio climatizado por } \\
\text { pressão positiva }\end{array}$ \\
\hline Núcleo PR 04 & Somente o arrendatário & $\begin{array}{l}\text { Um galpão arrendado climatizado por } \\
\text { pressão positiva }\end{array}$ \\
\hline Núcleo PR 05 & Somente o proprietário & $\begin{array}{l}\text { Um galpão próprio climatizado por } \\
\text { pressão positiva }\end{array}$ \\
\hline
\end{tabular}

A duração média de cada lote produzido, incluindo-se período de vazio sanitário posterior a cada ciclo de produção, foi de 60 dias, perfazendo um total de seis lotes ao ano. Considerando-se o entendimento de Hoffmann et al. (1992), Lampert (2003) e Reis (2007) sobre a possibilidade de se utilizar metodologia de análise simplificada para determinar a situação econômica de atividades agropecuárias e de Guiducci et al. (2012) sobre indicadores de eficiência econômica de interesse do empreendedor, adotou-se metodologia proposta por Reis (2007) e Conab (Custo..., 2010) para a análise de viabilidade econômica da atividade avícola.

\section{RESULTADOS E DISCUSSÃO}

Para ampliar as possibilidades de discussão dos resultados e das avaliações envolvendo escalas de produção, foram apresentados, na Tab. 2, os valores médios de produção e de produtividade dos oito núcleos avaliados.

Verifica-se que o núcleo IT 01 apresentou maior produtividade que os demais núcleos (Tab. 2). Tal fato deve-se à tecnologia de climatização utilizada nos galpões do núcleo IT 01 , pois aviários climatizados por pressão negativa permitem uma exploração mais acentuada dos espaços de criação. $\mathrm{Na}$ Tab. 3, foram resumidos os valores médios dos custos de produção, por ciclo de produção, em cada núcleo de criação de aves. 
Tabela 2. Número médio de aves alojadas, peso médio final, densidade média de alojamento e produtividade média, por ciclo de produção, em núcleos da empresa integradora (IT \#\#) e em núcleos de produtores rurais integrados (PR \#\#),

\begin{tabular}{ccccc} 
Núcleo & $\begin{array}{c}\text { Aves alojadas } \\
(\text { cabeças })\end{array}$ & Peso final $(\mathrm{kg})$ & $\begin{array}{c}\text { Densidade } \\
\left(\text { aves } / \mathrm{m}^{2}\right)\end{array}$ & Produtividade $\left(\mathrm{kg} / \mathrm{m}^{2}\right)$ \\
\hline IT 01 & 286.271 & 683.057 & 16,39 & 39,03 \\
IT 02 & 307.446 & 718.217 & 13,77 & 31,63 \\
IT 03 & 280.530 & 635.912 & 14,73 & 33,28 \\
PR 01 & 47.654 & 108.524 & 14,51 & 32,91 \\
PR 02 & 65.640 & 156.427 & 14,00 & 33,23 \\
PR 03 & 28.867 & 70.390 & 13,75 & 33,52 \\
PR 04 & 24.421 & 55.441 & 14,45 & 32,81 \\
PR 05 & 8.000 & 18.533 & 13,68 & 31,68 \\
\hline
\end{tabular}

Tabela 3. Custo operacional efetivo total (COEMe), custo com mão de obra familiar (MOFMe), custo com depreciação (DeprMe), custo alternativo (CAltMe), custo operacional total (COTMe) e custo total de produção (CTMe), por ciclo de produção, em reais por quilograma de peso vivo produzido, para núcleos da empresa integradora (IT \#\#) e para núcleos de produtores rurais integrados (PR \#\#)

\begin{tabular}{ccccccc}
\hline Núcleo & COEMe & MOFMe & DeprMe & CAltMe & COTMe & CTMe \\
\hline IT 01 & 0,3196 & 0,0000 & 0,0585 & 0,0413 & 0,3781 & 0,4195 \\
IT 02 & 0,4330 & 0,0000 & 0,0000 & 0,0047 & 0,4330 & 0,4376 \\
IT 03 & 0,3532 & 0,0000 & 0,0442 & 0,0274 & 0,3974 & 0,4248 \\
PR 01 & 0,1632 & 0,0494 & 0,0501 & 0,0394 & 0,2628 & 0,3021 \\
PR 02 & 0,1992 & 0,0292 & 0,0481 & 0,0519 & 0,2765 & 0,3284 \\
PR 03 & 0,1352 & 0,0575 & 0,0453 & 0,0442 & 0,2380 & 0,2822 \\
PR 04 & 0,2222 & 0,0482 & 0,0000 & 0,0029 & 0,2704 & 0,2733 \\
PR 05 & 0,1832 & 0,1440 & 0,0529 & 0,0580 & 0,3801 & 0,4381 \\
\hline
\end{tabular}

Em se tratando da produção em unidades de produção integrada, segundo Caldas et al. (2015), o CTMe em aviários climatizados por pressão positiva foi de $\mathrm{R} \$ 0,2416$ por quilograma de peso vivo produzido. De acordo com a Tab. 3, para os núcleos de produtores rurais (excluindose o núcleo PR 05, que apresentou resultados discrepantes - outlier, discutidos com base em informações presentes na Fig. 1), o CTMe foi de $\mathrm{R} \$ 0,2965$ por quilograma, o que indica um aumento de $22,7 \%$ no custo de produção. Sugere-se que essa variação tenha ocorrido devido a correções monetárias vinculadas ao espaço de tempo decorrido entre as análises ou devido a diferenças nos preços dos insumos entre as regiões avaliadas em cada pesquisa.

Constata-se ainda que os CTMe de núcleos pertencentes à empresa integradora foram maiores que os observados para núcleos de produção via contrato de integração - com exceção do núcleo PR 05. Em média, o CTMe para os núcleos da empresa integradora foi aproximadamente $44 \%$ maior que para núcleos pertencentes aos produtores integrados, excluindo-se o núcleo PR 05 dessa avaliação (Tab. 3). Análises sobre a composição do CTMe indicaram que o custo médio com mão de obra (MO) causou maior impacto sobre o desempenho econômico de núcleos da empresa integradora em relação aos núcleos de produtores integrados. Isso posto, o custo com MO foi apresentado na Fig. 1 de acordo com suas categorias: MO contratada permanente, MO contratada temporária (contratação de diaristas para retirada ou movimentação de cama e para limpeza e desinfecção das instalações) e MO familiar. 


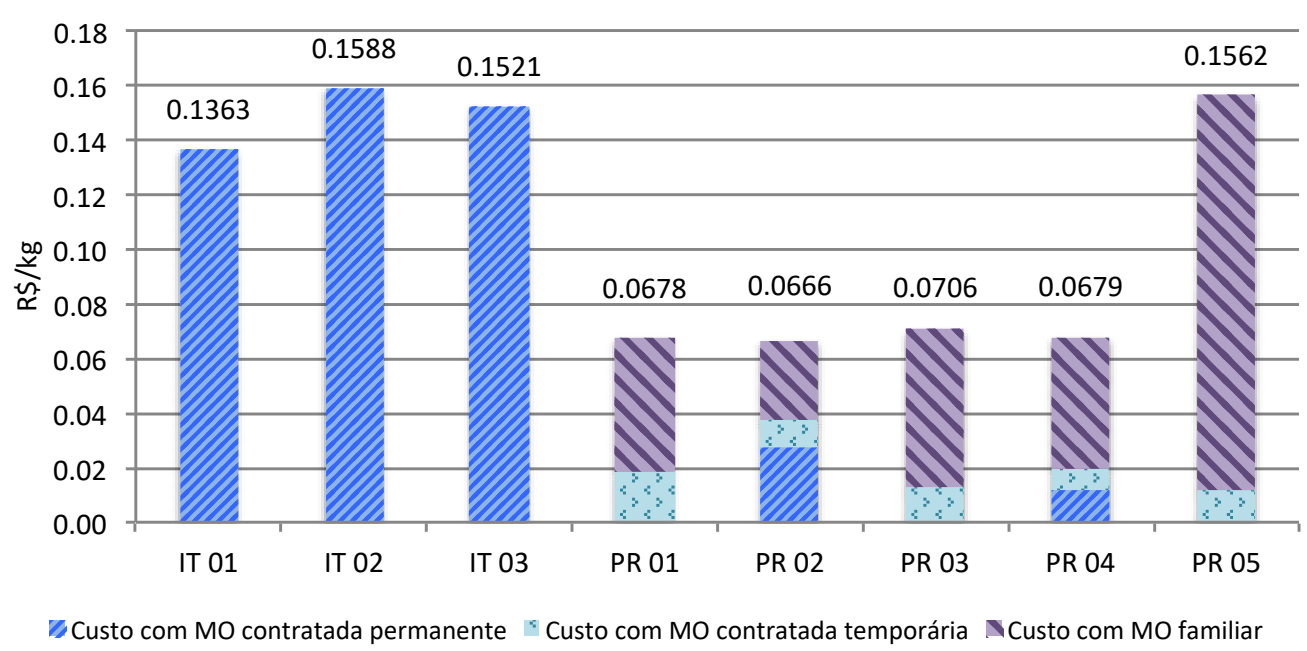

Figura 1. Custo com mão de obra (MO), conforme suas categorias, por ciclo de produção, em reais por quilograma de peso vivo produzido, para núcleos da empresa integradora (IT \#\#) e para núcleos de produtores rurais integrados (PR \#\#).

Destaca-se, na Fig. 1, que o núcleo PR 05 se configurou como caso atípico (outlier) em razão de sua incapacidade de diluir custos fixos. A análise da Tab. 2 evidencia que, embora sua produtividade, em quilos por metro quadrado, seja compatível com a de seus pares, sua reduzida produção de aves não lhe proporcionou denominador suficiente para reduzir seu custo com MO familiar. Observa-se, na Fig. 1, que o custo com MO em núcleos da empresa integradora foi maior que o apresentado nos núcleos de produção integrada. Sem considerar o núcleo PR 05 (outlier), a média dos custos com MO em núcleos de produtores rurais ( $\mathrm{R} \$$ $0,068 / \mathrm{kg}$ ) correspondeu a menos da metade do valor gasto em média pela empresa integradora ( R\$ 0,149/kg).

Outro aspecto retratado na Fig. 1 refere-se aos custos totais com MO para os núcleos de produção integrada, que apresentaram reduzida diferença entre si, desconsiderando-se o núcleo PR 05. Isso demonstra que o custo associado à MO convergiu para valor comum, determinado provavelmente pela quantidade de força de trabalho necessária para operacionalizar a atividade, independentemente do tipo de MO utilizada (MO contratada permanente, contratada temporária ou familiar). Em se tratando de valores relativos, o custo médio com MO para os núcleos da empresa integradora representou
43,9\% do COE, descontado do custo com aluguel (descontou-se o valor do custo com aluguel para a referida comparação de médias, com vistas a evitar distorções no $\mathrm{COE}$ do núcleo IT 02 e do núcleo PR 04, cujas instalações eram arrendadas), e, para os núcleos de produtores rurais, esse valor foi de $41,7 \%$. Em comparação com os dados da Faep (Boletim..., 2016), verifica-se que o impacto desse custo sobre os desembolsos nos núcleos avaliados no estado de Minas Gerais foi maior que o apresentado na produção paranaense, cujo valor representou $34,0 \%$ do COE.

A despeito de os custos com MO para os núcleos pertencentes à empresa integradora terem se assemelhado numericamente a esse mesmo custo para núcleo PR 05, as razões que justificam os valores encontrados são distintas entre si. Enquanto para o núcleo PR 05 inexistiu possibilidade estrutural para alojamento de aves em quantidade suficiente para diluição de custos fixos, o elevado custo com MO para os núcleos IT 01, IT 02 e IT 03 assentou-se sobre questões vinculadas ao gerenciamento e à contratação de recursos humanos. Na Tab. 4, encontram-se informações sobre a área total de criação, a quantidade de trabalhadores permanentes e a proporção em metros quadrados por trabalhador para cada núcleo de criação de aves. 
Tabela 4. Emprego de mão de obra por núcleo da empresa integradora (IT \#\#) e por núcleo de produtores rurais integrados (PR \#\#)

\begin{tabular}{cccc} 
Núcleo & $\begin{array}{c}\text { Área total de criação } \\
\left(\mathrm{m}^{2} / \text { núcleo }\right)\end{array}$ & $\begin{array}{c}\text { Trabalhadores permanentes* } \\
\text { (pessoas) }\end{array}$ & $\begin{array}{c}\text { Área por trabalhador } \\
\left(\mathrm{m}^{2} / \text { pessoa }\right)\end{array}$ \\
\hline IT 01 & 18.085 & 21 & 861,19 \\
IT 02 & 23.185 & 25 & 927,42 \\
IT 03 & 19.730 & 21 & 939,52 \\
PR 01 & 3.300 & 2 & 1650,00 \\
PR 02 & 4.707 & 2 & 2353,50 \\
PR 03 & 2.100 & 1,5 & 1400,00 \\
PR 04 & 1.690 & 1 & 1690,00 \\
PR 05 & 585 & 1 & 585,00 \\
\hline
\end{tabular}

*Como diaristas contratados para retirada de cama e para limpeza e desinfecção dos aviários não foram incluídos no cálculo do uso de mão de obra para núcleos de produção integrada, as equipes de trabalho contratadas pela empresa integradora, para executar essas mesmas tarefas, também não foram consideradas nessa tabela.

Segundo Miele et al. (2010b), galpões climatizados por pressão negativa demandam um trabalhador para cada 2.800 metros quadrados de área de criação e galpões de pressão positiva, 1.500 metros quadrados por pessoa. De acordo com os dados presentes na Tab. 4, aponta-se que o elevado custo relativo com MO nos núcleos de criação da empresa integradora e no núcleo PR 05 deve-se provavelmente à proporção inadequada de trabalhadores por metro quadrado para operacionalização da atividade avícola. Destaca-se ainda, na mesma tabela, que o núcleo PR 02 apresentou o maior aproveitamento de MO por metro quadrado que seus pares, inclusive em melhor proporção que o previsto por Miele et al. (2010b). Entretanto, apesar dessa informação, o custo médio com MO para o núcleo PR 02 não apresentou diferença significativa em relação aos demais núcleos de produção integrada (Fig. 1), pois o emprego de MO contratada contribuiu para a elevação desse custo.

Segundo Guanziroli et al. (2003), Alves (2006) e Campolina e Silveira (2008), a contratação permanente de recursos humanos implica elevação do custo com $\mathrm{MO}$, principalmente em virtude de encargos que incidem sobre a folha de pagamento dos trabalhadores, da escassez de MO capacitada para serviços de maior complexidade tecnológica e da competição por MO em setores rurais não agrícolas e urbanos. Em contrapartida, a utilização da força de trabalho familiar ajuda a reduzir custos de produção, pois sobre a remuneração calculada não incidem obrigatoriamente encargos trabalhistas e sociais, pagamentos de hora extra e repouso remunerado, além de seguros e coberturas por acidentes de trabalho (Alves, 2006).

Embora o uso da MO familiar se configure como melhor alternativa financeira do que a contratação de recursos humanos, esse é o lado perverso do sistema de integração agropecuária. De modo geral, parcela da redução de custos na cadeia avícola de corte se deve à exploração do trabalho em pequenas unidades de produção familiar, nas quais não existe remuneração adicional para trabalhos exercidos além da jornada de trabalho regulamentar (Jesus, 2012; Nogueira e Jesus, 2013). A despeito de a empresa integradora não remunerar seus próprios núcleos de criação pela produção de aves, para possibilitar a realização das análises econômicas propostas, foram calculadas as receitas que seriam pagas às unidades de criação da empresa integradora como se elas funcionassem sob regime de integração. Desse modo, as receitas totais, compostas pelas receitas primárias (remuneração pelas aves produzidas) e pelas receitas secundárias (obtidas com a venda de cama produzida nos aviários), por lote criado em cada núcleo de produção, encontram-se na Fig. 2. 


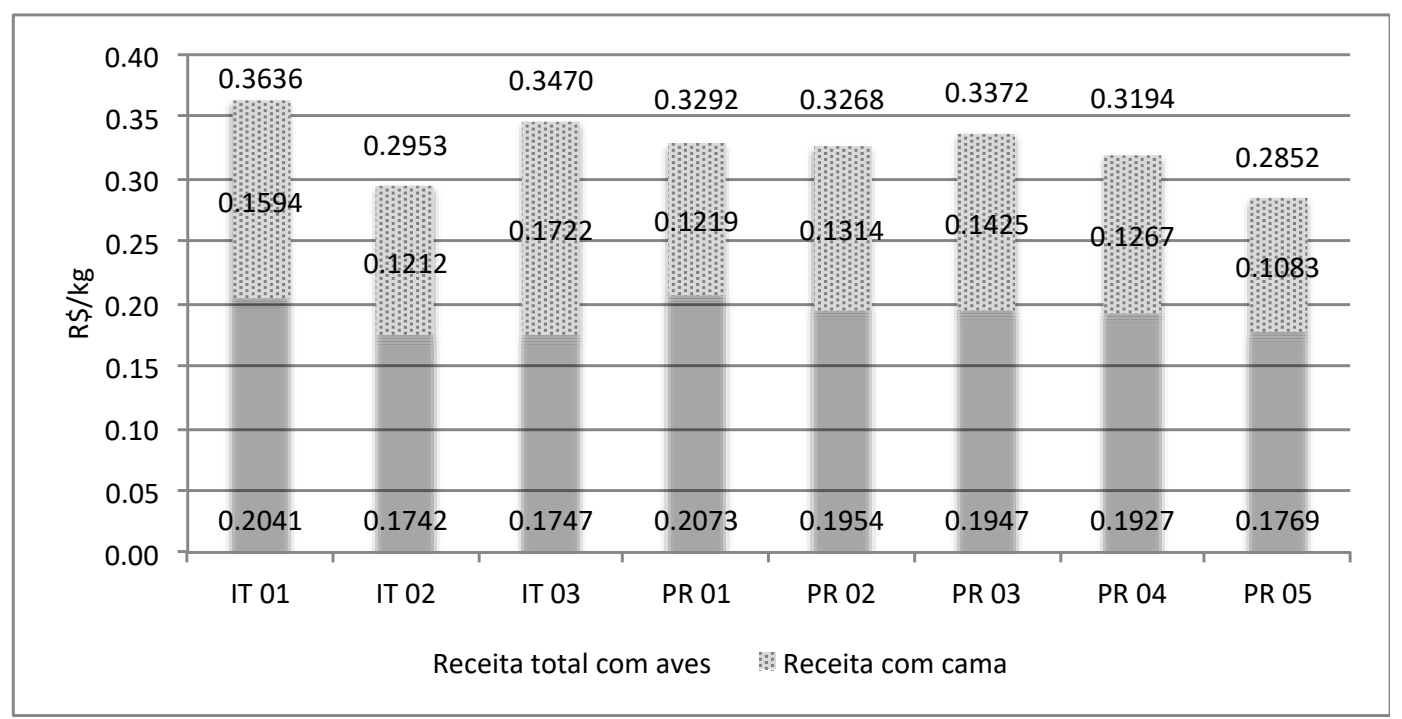

Figura 2. Receitas totais, por categorias que as compõem por ciclo de produção, em reais por quilograma de peso vivo produzido, para núcleos da empresa integradora (IT \#\#) e para núcleos de produtores rurais integrados (PR \#\#).

O núcleo IT 01 foi aquele que apresentou a maior receita total por ciclo de produção, seguido pelos núcleos IT 03 e PR 03, nessa ordem (Fig. 2). Entretanto, o comportamento desses resultados deve-se à participação de receitas provenientes da venda de cama, visto que, em média, os núcleos da empresa integradora obtiveram receitas secundárias $19,6 \%$ maiores que a recebida pelos núcleos de produção via contratos de integração. Nesse contexto, ao se descontarem as receitas secundárias, as maiores receitas primárias foram obtidas pelos núcleos PR 01 e núcleo IT 01, seguidos pelos núcleos PR 02, PR 03 e PR 04. Para núcleos de produção sob contratos de integração, a comparação dos custos totais (Tab. 3) e de receitas primárias (Fig. 2), obtidos nesta pesquisa com dados de Caldas et al. (2015), indicam que, enquanto o custo total de produção se elevou $22,7 \%$, a variação da receita foi de aproximadamente $5,5 \% \quad(\mathrm{R} \$$ 0,18/kg para o artigo citado e $\mathrm{R} \$ 0,19 / \mathrm{kg}$ para os núcleos avaliados nesta pesquisa). Apesar do intervalo de tempo entre as análises e das diferenças regionais, verifica-se acentuado descompasso nas variações de custos e receitas entre as pesquisas realizadas.

A análise dos resultados econômicos foi dividida em dois cenários. No primeiro, foram confrontados custos com receitas totais obtidas na atividade, ao passo que, no segundo, apenas as receitas primárias (provenientes da remuneração pelas aves produzidas) foram consideradas nas análises, ou seja, não foram incluídas as receitas obtidas com a venda de cama produzida nos aviários (receitas secundárias). Valores médios de $\mathrm{COE}$, de custo com MO familiar, de custo com depreciação, de custo alternativo e de receitas totais foram expostos na Fig. 3 e os valores médios de lucro operacional e lucro total, na Tab. 5.

A análise dos resultados apresentados na Fig. 3 e na Tab. 5 indica que a atividade avícola de corte foi capaz de gerar lucro somente na criação de aves via contrato de integração (governança híbrida), ao passo que a produção em núcleos de galpões da empresa integradora (governança via hierarquia) implicou prejuízo financeiro. Situação de lucro econômico, na qual as receitas superam os custos totais, foi observada para o núcleo PR 01, núcleo PR 03 e núcleo PR 04. Para esses núcleos, a atividade avícola de corte via contratos de integração gerou lucro superior ao que seria obtido pelo investimento dos recursos na caderneta de poupança. De acordo com Reis (2007), a tendência seria de expansão das atividades nesses núcleos em médio e longo prazos. 


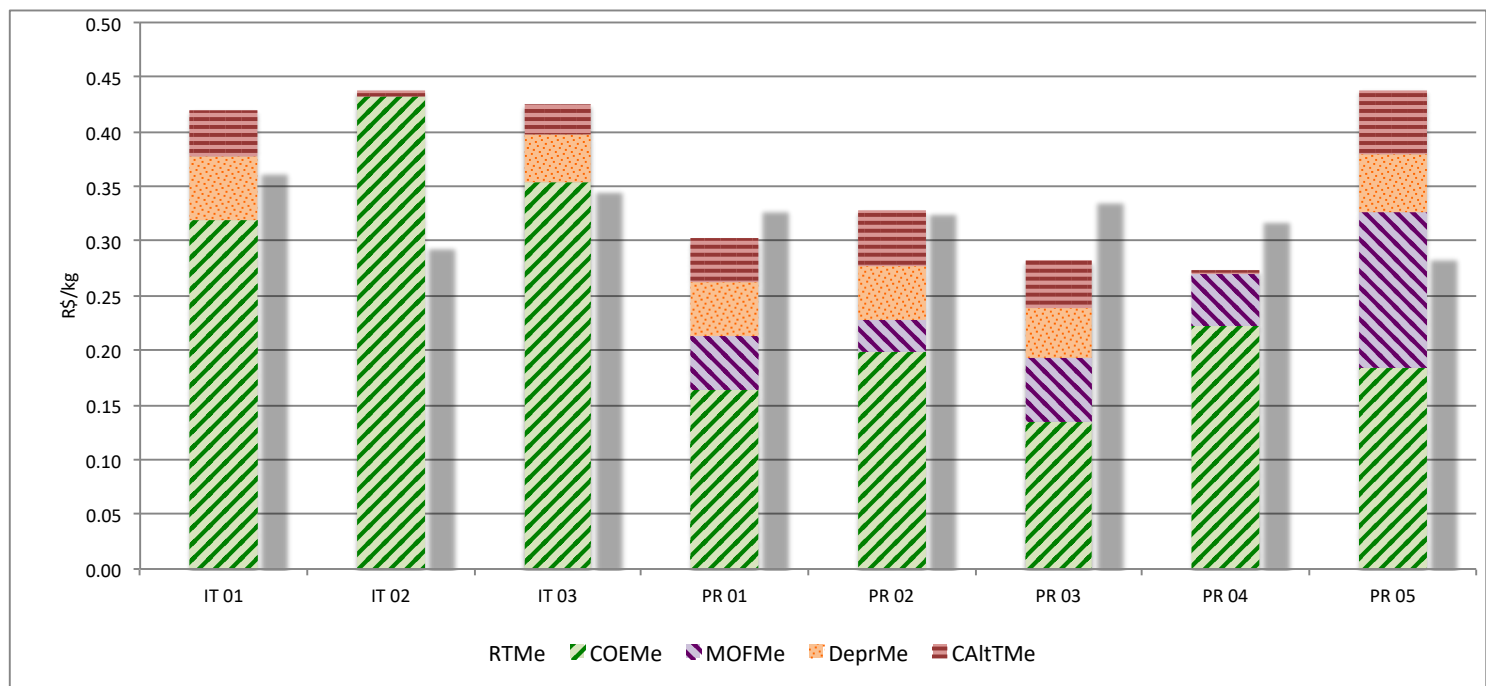

Figura 3. Análise econômica considerando receita total (RTMe), custo operacional efetivo (COEMe), custo com mão de obra familiar (MOFMe), depreciação (DeprMe) e custo alternativo total (CAltMe) por ciclo de produção, em reais por quilograma de peso vivo produzido, para núcleos da empresa integradora (IT \#\#) e para núcleos de produtores rurais integrados (PR \#\#)

Tabela 5. Lucro operacional e lucro total por ciclo de produção, com base na receita total, em reais por quilograma de peso vivo produzido, para núcleos da empresa integradora (IT \#\#) e para núcleos de produtores rurais integrados (PR \#\#)

\begin{tabular}{|c|c|c|c|c|c|c|c|c|}
\hline & IT 01 & IT 02 & 03 & $\mathrm{R} 01$ & R 02 & R 03 & R 04 & PR 05 \\
\hline $\begin{array}{l}\text { Lucro } \\
\text { operacional }\end{array}$ & $\begin{array}{c}- \\
0,0146\end{array}$ & 76 & $-0,0505$ & 0,0664 & 3 & 0 , & 0 & $-0,0949$ \\
\hline Lucro to & 0,0559 & $-0,1423$ & $-0,0779$ & 0,0270 & $-0,0017$ & 0,0550 & 0,0461 & $-0,1529$ \\
\hline
\end{tabular}

Como as receitas obtidas no núcleo PR 02 foram praticamente iguais ao custo total de produção, a situação foi de lucro normal. Por conseguinte, os retornos da atividade seriam os mesmos em caso de aplicação do capital em fundos bancários de renda fixa. A tendência, nesse caso, seria que a atividade no núcleo se mantivesse estável, sem expansão ou retração (Reis, 2007). A receita total do núcleo IT 01 foi insuficiente para cobrir custos fixos, enquadrando-se em situação de resíduo nulo com cobertura parcial da depreciação. A tendência prevista para esse núcleo seria de interrupção da atividade à medida que a vida útil dos bens expirasse, haja vista o processo de descapitalização em curso (REIS, 2007). Enquanto isso, como os núcleos IT 02 e IT 03 não obtiveram receitas capazes de cobrir seus custos operacionais efetivos, suas situações eram de resíduo negativo. Assim, segundo Reis (2007), eles estariam propensos a suspender as atividades em curto prazo.
Contudo, embora a teoria econômica indicasse abandono da atividade pelos núcleos IT 01, IT 02 e IT 03, provavelmente, na prática, isso não se concretizaria, pois a empresa integradora não dividia o setor de criação de aves e o setor de abate de aves em centros de custos diferentes. Dessa maneira, recursos gerados no abatedouro da empresa eram utilizados para saldar deveres e obrigações dos núcleos de criação. O núcleo PR 05 também se encontrava em situação de resíduo negativo, com tendência de interrupção da atividade em curto prazo (REIS, 2007). Nesse caso, ao contrário da previsão teórica, o produtor se mantinha em atividade pelo sacrifício da remuneração de sua própria força de trabalho. Isso, entretanto, não alterou sua situação de insolvência em médio e longo prazos, pois, assim que expirada a vida útil de seus equipamentos e instalações, o produtor precisaria recorrer à captação de recursos externos para reposição do ativo depreciado. 
Indústrias abatedoras, ao optarem pela estrutura de governança híbrida, transferem custos operacionais, relacionados à criação das aves, para terceiros. Em contrapartida, nesse modelo de produção, as empresas integradoras devem remunerar os produtores integrados ao final de cada ciclo de produção. Independentemente da estrutura de governança adotada (híbrida ou via hierarquia), os custos com rações, pintos de um dia, serviço de apanha, assistência técnica, produtos veterinários e transportes ficam sob a responsabilidade da empresa integradora. A partir desses dois entendimentos, procedeu-se à simulação de resultados financeiros de acordo com dados coletados na pesquisa (Tab. 6).

Tabela 6. Simulação de resultados financeiros da criação de aves em galpões pertencentes à empresa integradora ou via contratos de integração, em reais por quilograma de peso vivo produzido e em valores absolutos

\begin{tabular}{|c|c|c|c|c|}
\hline & & \multicolumn{3}{|c|}{ Núcleo } \\
\hline & Valores médios coletados na pesquisa & IT 01 & IT 02 & IT 03 \\
\hline a & Receita total média com aves $(\mathrm{R} \$ / \mathrm{kg})$ & 0,2041 & 0,1742 & 0,1747 \\
\hline $\mathrm{b}$ & Receita total média com venda de cama $(\mathrm{R} \$ / \mathrm{kg})$ & 0,1594 & 0,1212 & 0,1722 \\
\hline $\mathrm{c}$ & $\begin{array}{l}\text { Custo operacional total médio }(\mathrm{R} \$ / \mathrm{kg}) \\
\text { Simulação de resultado por aviário }\end{array}$ & 0,3781 & 0,4330 & 0,3974 \\
\hline $\mathrm{d}=\mathrm{a}$ & $\begin{array}{c}\text { Custo estimado com remuneração de produtores } \\
\text { via contrato de integração ( } \mathrm{R} \$ / \mathrm{kg})\end{array}$ & 0,2041 & 0,1742 & 0,1747 \\
\hline $\begin{array}{c}e=c- \\
b\end{array}$ & $\begin{array}{l}\text { Capital efetivamente utilizado para produção de } \\
\text { aves em galpões próprios ( } \mathrm{R} \$ / \mathrm{kg} \text { ) }\end{array}$ & 0,2187 & 0,3118 & 0,2252 \\
\hline$f=d-e$ & $\begin{array}{c}\text { Diferença entre a criação de aves em galpões } \\
\text { próprios e a produção via contrato de integração } \\
(\mathrm{R} \$ / \mathrm{kg})\end{array}$ & $-0,0146$ & $-0,1376$ & $-0,0505$ \\
\hline & Simulação de resultado por núcleo & & & \\
\hline & Diferença por ciclo de produção $(\mathrm{R} \$)$ & $-9.972,63$ & $-98.826,66$ & $-32.113,56$ \\
\hline & Diferença por ano $(\mathrm{R} \$)$ & $-59.835,79$ & $\begin{array}{c}- \\
592.959,96 \\
\end{array}$ & $192.681,34$ \\
\hline
\end{tabular}

Por meio dos cálculos apresentados na Tab. 6, verifica-se que, para o núcleo IT 01 , o capital efetivamente utilizado na produção de aves em galpões pertencentes à integradora seria 7,15\% superior ao necessário para produção de aves em sistema de integração com produtores rurais. $\mathrm{Na}$ pior das hipóteses, observada para o núcleo IT 02, essa diferença chegaria a 78,99\%. Sob essa perspectiva, mantidas as demais condições constantes, a empresa integradora poderia economizar R\$ 845.477,08 ao ano, caso optasse produzir frangos de corte via contratos de integração em substituição à criação de aves em seus próprios núcleos de produção.

\section{CONCLUSÕES}

De acordo com os resultados das análises econômicas, indica-se que a estrutura de governança híbrida é a melhor alternativa econômica para criação de frangos de corte. Em comparação com núcleos de produção integrada, constatou-se elevado custo de produção no sistema de governança via hierarquia, devido principalmente ao custo com mão de obra empregada na operacionalização da atividade. Considerando que os investimentos em sistemas de criação são parcialmente irreversíveis e que alterações administrativas mais complexas podem implicar elevados custos de transação, acredita-se que a interrupção da produção de aves em galpões próprios não seja a melhor alternativa para as empresas integradoras. Entretanto, com o objetivo de minimizar perdas, além de considerar fatores de mercado que justifiquem a utilização de galpões próprios, sugere-se que empresas integradoras tentem esgotar todas as possibilidades de produção via contrato de integração antes de investirem em instalações próprias de criação. 


\section{REFERÊNCIAS}

ALVES, E. Migração rural-urbana, agricultura familiar e novas tecnologias: coletânea de artigos revistos. Brasília: Embrapa Informação Tecnológica, 2006. 181p.

BOLETIM informativo. Curitiba: FAEP, n.1350, $2016 . \quad$ Disponível em: <https://issuu.com/sistemafaep/docs/bi_1350>. Acesso em: 02 dez. 2018.

CALDAS, E.O.L.; LARA, L.J.C.; CARDEAL, P.C.; MATIAS, C.F.Q. Análise econômica da produção de frangos de corte sob contratos de integração em pequenas unidades familiares. Organizações Rurais \& Agroindustriais., v.17, p.351-368, 2015

CAMPOLINA, B.; SILVEIRA, F.G. O mercado de trabalho rural: Evolução recente, composição da renda, e a dimensão regional. In: DEDECCA, C.; BUAINAIN, A. (Orgs.). Desenvolvimento rural sustentável. Brasília: IICA, 2008. p.211245.

CUSTOS de produção agrícola: a metodologia da Conab. Brasília: Conab, 2010. 60p.

GIROTTO, A.F.; SOUZA, M.V.N. Metodologia para o cálculo do custo de produção de frango de corte: versão 1. Concórdia: Embrapa Suínos e Aves, 2006. 28p. (Série Documentos, 109).

GUANZIROLI, C.E.; ROMEIRO, A.; BUAINAIN, A.M. Agricultura familiar e novo mundo rural. Sociologias, v.5, p.312-347, 2003.

GUIDUCCI, R.C.N.; ALVES, E.R.A.; LIMA FILHO, J.R.; MOTA, M.M. Aspectos metodológicos da análise de viabilidade econômica de sistemas de produção In: GUIDUCCI, R.C.N.; LIMA FILHO, J.R.; MOTA, M.M. (Eds.). Viabilidade econômica de sistemas de produção agropecuários: metodologia e estudos de caso. Brasília, DF: Embrapa, 2012. p.17-78.
HOFFMANN, R.; ENGLER, J.J.C.; SERRANO, O.; et al. Administração da empresa agrícola. 7.ed. São Paulo: Pioneira, 1992. v.1, 325p.

JESUS, E.A integração avícola catarinense: o trabalho precarizado oculto na contratualização. Em Pauta, v.10, p.103-127, 2012.

LAMPERT, J.A. Caderno didático de administração rural. In:. Administração Rural. Santa Maria: DEAER/UFSM, 2003. 121p.

MATSUNAGA, M.; BEMELMANS, P.F.; TOLEDO, P.E.N.; et al. Metodologia do custo de produção utilizada pelo IEA. Agricultura em São Paulo, v.23, p.123-139, 1976.

MIELE, M.; MARTINS, F.M.; SANTOS FILHO, J.I.; SANDI, A.J. Metodologia para o cálculo do custo de produção de frango de corte: versão 2. Concórdia: Embrapa Suínos e Aves, 2010a. 23p. (Série Documentos, 140).

MIELE, M.; ABREU, P.G.; ABREU, V.M.N. et al. Coeficientes técnicos para o cálculo do custo de produção de frango de corte. Concórdia: Embrapa Suínos e Aves, 2010b. 14p. (Comunicado técnico, 483).

NOGUEIRA, C.M.; JESUS, E.A. Pequena produção avícola familiar e o sistema de integração no oeste catarinense: "uma prisão de portas abertas". Caderno CRH, v.26, p.123-138, 2013.

REIS, R.P. (Org.). Fundamentos de economia aplicada. Lavras: UFLA/FAEPE, 2007. v.1, 95p

YIN, R.K. Estudo de caso: planejamento e métodos. Tradução de Daniel Grassi. 3.ed. Porto Alegre: Bookman, 2005. 212p. 